\title{
ABORDAGENS DO SISTEMA PENAL A PARTIR DA OBRA DE ROBERTO ESPOSITO
}

\section{APPROACHING THE CRIMINAL SYSTEM THROUGH ROBERTO ESPOSITO}

\author{
Clara Maria Roman Borges \\ Universidade Federal do Paraná - UFPR - (Curitiba, PR, Brasil) \\ Universidade Positivo (Curitiba, PR, Brasil) \\ Nikolai Olchanowski \\ Universidade Federal Fluminense - UFF - (Niterói, RJ, Brasil) \\ Universidade do Contestado (Mafra, SC, Brasil) \\ Recebimento: 13 jul. 2018 \\ Aceitação: 20 nov. 2018
}

\begin{abstract}
Como citar este artigo / How to cite this article (informe a data atual de acesso / inform the current date of access):
\end{abstract}
BORGES, Clara Maria Roman; OLCHANOWSKI, Nikolai. Abordagens do sistema penal a partir da obra de Roberto Esposito. Revista da Faculdade de Direito UFPR, Curitiba, PR, Brasil, v. 63, n. 3, p. 189-212, set./dez. 2018. ISSN 2236-7284. Disponível em: <https://revistas.ufpr.br/direito/article/view/60497>. Acesso em: 22 dez. 2018. DOI: http://dx.doi.org/10.5380/rfdufpr.v63i3.60497.

\section{RESUMO}

Redigido na forma de ensaio, o artigo sugere como produtiva uma abordagem do sistema penal por meio da obra de Roberto Esposito, especialmente a partir de dois conceitos recorrentes no pensamento do filósofo italiano: imunização e comunidade. Primeiro, é ressaltada a proximidade entre a concepção de pena fornecida e a lógica imunitária. Mediante o mecanismo da apropriação a comunidade política internaliza o elemento do qual pretende se proteger, operando a partir de negatividades. $\mathrm{O}$ caráter aflitivo da pena aloca a violência em um espaço controlado, criando uma forma de mediação para a proteção do comum, o que faz surgir o perene risco de autodestruição, na forma de crise autoimune. Depois, como um alerta às promissoras produções em torno do que se chamou de práticas restaurativas, aponta-se para o perigo de essencialização da noção de comunidade. Segundo Esposito, pensar a comunidade exige se afastar do léxico político-filosófico moderno, sob pena de perverter o próprio conceito.

\section{PALAVRAS-CHAVE}

Roberto Esposito. Sistema penal. Imunização. Comunidade. Justiça restaurativa.

\section{ABSTRACT}

This essay suggests as fruitful an approach to the criminal system through the work of Roberto Esposito, especially by using two recurring concepts of the Italian philosopher's thinking: immunization and community. At first, it demonstrates the proximity between punishment and the immunitary logic. By using the appropriation mechanism, the political community internalizes what it wishes to be protected from, operating through negativities. The harmful element of punishment allocates violence in a controlled space, creating a form of mediation for the protection of what is common. This strategy creates the perennial risk of self-destruction in the form of autoimmune crisis. Then, as a warning to the promising writings about restorative practices, this essay points at the danger 
of essentializing the notion of community. According to Roberto Esposito, perceiving the meaning of community demands a departure from the modern political-philosophical lexicon. Otherwise, the concept of community itself would be perverted.

\section{KEYWORDS}

Roberto Esposito. Criminal system. Immunization. Community. Restorative justice.

\section{INTRODUÇÃO}

O presente escrito tem por objetivo a apresentação dos resultados de uma pesquisa filosófica aplicada, que buscou identificar na obra de Roberto Esposito ferramentas para se refletir sobre a pena e o sistema penal contemporâneos.

Trata-se de um ensaio porque pretende aprofundar e arejar o modo como são trabalhadas as críticas externas (ou transcendentes ${ }^{1}$ ) a problemas filosóficos sempre recorrentes nas teorizações sobre a justificação da pena e na violência intrínseca do sistema penal, bem como problematizar as novas propostas pensadas para responder às situações que nos acostumamos a denominar de crimes.

A escolha desse filósofo italiano para revisitar questões tantas vezes discutidas e provocar um novo olhar inclusive sobre as críticas a determinados dogmas da modernidade relativos à pena e ao sistema penal não se deu porque sua obra é vista como uma referência obrigatória para pensar a resposta penal estatal dirigida a determinados comportamentos e indivíduos. Da mesma maneira, com esta opção não se quis forçar uma leitura simplificadora de ideias, buscando demonstrar que nos textos espositianos estariam contidas as respostas prontas para perguntas recorrentes durante tanto tempo entre estudiosos da temática. Ao contrário, elegeu-se a obra de Roberto Esposito para nortear esta pesquisa porque se percebeu uma angustiante saturação na leitura do sistema penal que vem sendo realizada pelos autores da área jurídica, principalmente em razão da falta de percepção do potencial crítico de ricas tradições de pensamento filosófico ${ }^{2}$ ainda pouco exploradas naquele universo e do conforto teórico representado pela insistência em certas ideias que não mais servem para traduzir a realidade da punição estatal (se é que em algum momento o fizeram).

Ao apontar para uma leitura da modernidade por intermédio do que ele chama de paradigma imunitário (ESPOSITO, 2008, p. 45-77), Esposito desnuda aporias que sempre vêm à tona nas discussões filosóficas, mas poucas vezes são diretamente enfrentadas. A primeira e mais fundamental delas é a formulação da modernidade em torno do esforço de preservação da vida justamente pela

\footnotetext{
${ }^{1}$ Utiliza-se a dicotomia crítica imanente/crítica transcendente, na forma como proposta em Losano (2010, p. 128-132).

${ }^{2}$ Como exemplo mais dramático, basta tomar a redução perpetrada por juristas no pensamento marxista ou na obra de Michel Foucault. Especificamente sobre a pena e o sistema penal, essas duas correntes tão distintas de pensamento chegam ao cúmulo de serem equalizadas, como se manifestassem a mesma (e facilmente identificável) direção.
} 
manutenção muito próxima de sua negação. Isto é, afirma-se a vida não pela supressão da morte (e do medo, da violência, da irracionalidade), mas sim pela sua reprodução controlada, pela sua neutralização (ESPOSITO, 2011, p. 8, 2012a, p. 61).

A consequência disso é justamente a perene possibilidade de inversão perversa do aparato destinado à proteção da vida em um aparato produtor de morte - é aqui que surge um imediato horizonte biopolítico, que obriga Esposito não só a retornar às originais reflexões de Foucault ${ }^{3}$, como a reformular a própria posição da política em relação à complexa ideia de vida (ESPOSITO, 2008, p. 13-44). Ante essa problemática, a constante preocupação de Esposito parece ser pensar a possibilidade de uma política da vida sem cair em uma política sobre a vida ou, em outros termos, uma biopolítica que não se torne tanatopolítica (ESPOSITO, 2008, p. 194).

Considerando essas premissas, entende-se que para pensar o sistema penal a partir das ferramentas espositianas primeiramente é necessário compreender que o direito, por meio do mecanismo de apropriação (ESPOSITO, 2011, p. 21-51), realiza uma clara função imunizante, protegendo a comunidade pela utilização de um instrumento que contém o germe da sua própria destruição, isto é, por meio da internalização da violência. Inclusive, uma consulta à vasta bibliografia que trata a pena como imposição intencional de dor a um indivíduo faz perceber que os termos com que Esposito trabalha não estão distantes, pois reconduzem a ideia de um direito como imunização formulada pelo léxico moderno - com especial clareza em Hobbes (ESPOSITO, 2012a, p. 53-82) -, porém ao mesmo tempo apresentando inúmeras novas possibilidades de abordagem do chamado “problema da pena” (BOONIN, 2008, p. 1).

Além disso, o pensamento de Esposito pode fornecer importantes instrumentos para analisar uma das mais promissoras tentativas de reconstrução de respostas a conflitos, que busca desvincular os mecanismos de censura das respostas aflitivas e reúne os teóricos agrupados sob a ideia de justiça restaurativa (GIAMBERARDINO, 2015). Como bem demonstra Fernanda Rosenblatt (2014), a grande fragilidade desses teóricos recai sobre um dos pontos fundamentais de suas reflexões: a noção de comunidade, vista como catalisadora da resolução dos conflitos. Essa noção é também central para o filósofo italiano, que a situa como o oposto conceitual de imunidade, pois estar em com-unidade é não estar imune (ESPOSITO, 2011, p. 5). Ao pensar com profundidade a ideia de comunidade, especialmente por afastar as absolutizações e ingenuidades que caracterizaram a forma com que ela foi por diversas vezes trabalhada, Esposito parece constituir um importante farol crítico para pensar as fragilidades da proposta da justiça restaurativa.

\footnotetext{
${ }^{3}$ Em especial: Foucault (1988, p. 125-151, 1999, p. 285-315).
} 
Portanto, esclarece-se que o sentido e o objetivo deste texto não ultrapassam uma inicial reflexão sobre direções para pensar a pena e o seu entorno teórico, apresentando-se como incipiente exercício teórico que busca fazer avançar o conhecimento sobre o sistema penal a partir das trilhas abertas pelas originais ideias de Roberto Esposito.

\section{LÓGICA IMUNITÁRIA}

Um dos temas recorrentes na obra de Roberto Esposito, como ele mesmo admite (ESPOSITO, 2012b, p. 11-32), é a tentativa de reler o léxico da filosofia política da modernidade, situando-o diante do momento presente. É nesse caminho que seu pensamento apontou para a “questão da comunidade” (ESPOSITO, 2012a, p. 10), especialmente impulsionado pelo crescente processo de essencialização da noção, com catastróficas consequências práticas ${ }^{4}$ e impeditivo de pensar efetivamente o estar-em-comum.

Esta essencialização promovida pela sociologia organicista da comunidade, pelo neocomunitarismo norte-americano e pelas diversas éticas da comunicação tornam a comunidade um “pleno", um "todo" ou um valor que se pode perder ou encontrar e que nos pertenceu em outros tempos, como uma origem remota e um destino a prefigurar. De qualquer maneira, nessas teorias o comum se identifica com seu oposto: a propriedade. Assim, o comum une numa única identidade a propriedade (étnica, territorial, espiritual) de cada um de seus membros; noutros termos, esses têm paradoxalmente em comum o que lhes é próprio, ao mesmo tempo que são proprietários do que lhes é comum (ESPOSITO, 2012a, p. 23-25).

Contudo, a busca pela “origem da coisa mesma”, de um ponto de partida determinável da comunidade, leva Esposito a pensar o comum como o oposto ao próprio. Comum é aquilo que não é próprio, que não é apropriável ${ }^{5}$. Em seu centro semântico está a ideia de munus, pensada como um dever que une os membros da comunidade, uma obrigação recíproca e mútua de dar, o que determina entre um e outro um compromisso. Esse dever, essa obrigação não é reconduzível a um sujeito

\footnotetext{
${ }^{4}$ Um dos mais efetivos recursos retóricos de Esposito é iniciar suas obras com exemplos concretos da atualidade e da dramaticidade do tema que será trabalhado. Assim, em Communitas (2012a, p. 21-49), são apresentadas as violências cometidas em nome da ideia de comunidade nos Balcãs, Timor, Congo, etc. Já Bíos (2011, p. 3-7) inicia com o que se poderia chamar de exemplos de biopolítica aplicada, como a decisão do governo russo de, conscientemente, sacrificar 128 reféns para mostrar pulso firme aos adversários chechenos ou o lançamento de bombas e mísseis no território afegão pelas mesmas aeronaves que, simultaneamente, lançavam medicamentos e alimentos.

${ }^{5}$ A ideia será trabalhada com mais detalhe ao longo do texto. Desde logo, contudo, percebe-se que ao identificar o comum ao que é impróprio, Esposito demarca um importante distanciamento em relação a várias formas de manejo atual da noção de comunidade. Pense-se, como exemplo bastante claro, na corrente dita comunitária da filosofia política contemporânea. Para breves referências: Gargarella (1999, p. 125-159); Duff (2001, p. 48-56).
} 
determinado. De fato, o que a caracteriza é justamente sua im-propriedade ou pertencimento, é um esvaziamento parcial ou integral da propriedade, que força o sujeito proprietário a sair de si mesmo, descentralizando-o. Isso significa que na comunidade os sujeitos não possuem um princípio de identificação, são ausentes de si mesmos, não sujeitos ou sujeitos da própria ausência, da ausência do próprio. Nas palavras do autor, o munus que a comunidade compartilha "é um dever que une os sujeitos da comunidade - no sentido de que te devo algo, mas você não me deve algo -, que faz com que não sejam inteiramente donos de si mesmos.”6 (ESPOSITO, 2012a, p. 30). Assim, o munus consiste ao mesmo tempo em dom e obrigação, benefício e prestação, conjunção e ameaça.

Portanto, sujeitos em comunidade perdem sua propriedade mais própria, sua subjetividade, pois na relação de obrigação em que se encontram saem de si, extrapolam os limites de si mesmos. Justamente por isso estar em comunidade traz consigo um duplo sentido: essa experiência é extremamente rica - “a mais extrema de suas possibilidades” (ESPOSITO, 2012a, p. 32) -, mas está longe de ser uma experiência tranquila e indolor.

O que existe entre os sujeitos em comunidade é uma impropriedade, isto é, uma relação que não pode ser resumida a um indivíduo ou a um grupo de indivíduos que partilham com outros certas características. Por isso, a comunidade é fundada num vazio, num espaço de profunda indeterminação entre os seres que a integram, no qual a afirmação do “eu” e do “outro” é impedida (NALLI, 2013, p. 84). O comum é inseparável do nada (melhor, é um nada) e, por isso, é insuportável.

O tema da imunidade aparece de imediato e como resposta ao caráter ambivalente da comunidade: os sujeitos modernos constituem-se pela liberação dos custos de estarem verdadeiramente em comunidade, isto é, “[...] a modernidade se afirma separando-se violentamente de uma ordem cujos benefícios não parecem compensar os riscos que comportam [...]” (ESPOSITO, 2012a, p. 40) ${ }^{7}$.

\footnotetext{
6 “Imponemos así un giro de ciento ochenta grados a la sinonimia común-proprio, inconscientemente, presupuesta por las filosofías comunitarias, y restablecemos la oposición fundamental: no es lo proprio, sino lo impropio - o, más drásticamente, lo otro - lo que caracteriza a lo común. Un vaciamiento, parcial o integral, de la propiedad en su contrario. Una desapropiación que inviste y descentra al sujeto propietario, y lo fuerza a salir de sí mismo. A alterarse. En la comunidad, los sujetos no hallan un principio de identificación [...]. No encuentran sino ese vacío, esa distancia, ese extrañamiento que los hace ausentes de sí mismos [...]. No sujetos. O sujetos de su propia ausencia, de la ausencia de proprio". Tradução livre: "Realizamos, assim, um giro de cento e oitenta graus à sinonímia comum-próprio, inconscientemente pressuposta pelas filosofias comunitárias, e reestabelecemos a oposição fundamental: não é o próprio, senão o impróprio - ou, mais drasticamente, o outro - o que caracteriza o comum. Um esvaziamento, parcial ou integral, da propriedade em seu contrário. Uma desapropriação que investe e descentraliza o sujeito proprietário, força-o a sair de si mesmo. Na comunidade, os sujeitos não possuem um princípio de identificação [...]. Não encontram senão esse vazio, essa distância, esse estranhamento que os faz ausentes de si mesmos [...]. Não sujeitos. Ou sujeitos de sua própria ausência, da ausência do próprio”.

7 Tradução livre. No original: “[...] la modernidad se afirma separándose violentamente de un orden cuyos beneficios no parecen compensar los riesgos que comportan [...]”.
} 
Só assim é possível captar o sentido de imunidade, pela negação explícita de comunidade. Imune é aquele que está livre do munus, da obrigação, aquele que é posto para fora da relação de reciprocidade exigida pela comunidade. O imune esvazia o comum, extinguindo seus efeitos e pressupostos; portanto quem é imune não deve nada, pois sua situação é de exceção.

A imunização é o recurso que a modernidade emprega para verdadeiramente individualizar os seres humanos, retirá-los de um estado de indistinção, do risco do vazio que representa estar em comunidade, negando o munus, desobrigando o indivíduo com os outros. Nesse sentido, a função maior do sistema imunitário é interromper a reciprocidade tributária da comunidade, neutralizando a força, a ameaça, o risco da dívida a ser paga, do vazio que compromete a existência individual dos integrantes da comunidade (NALLI, 2013, p. 86).

Esposito mostra de forma clara que a imunização é necessária, cumprindo-lhe a imprescindível tarefa de nos colocar a salvo dos riscos de estar em comum, contudo o faz justamente por meio da negação radical da comunidade, pela afirmação de seu oposto (ESPOSITO, 2009, p. 111).

O léxico da imunização remete para uma linguagem imediatamente médica, mas não exatamente para os recorrentes transplantes de conceitos médico-biológicos realizados para pensar a política, a exemplo dos organicismos e da ideia do corpo social como corpo em equilíbrio. Ao contrário, a imunização se apresenta na transformação do saber médico pré-moderno e conduz à ideia de um corpo saudável e íntegro, que deve ser protegido por meio de ataques às ameaças externas e afirma-se com mais força um princípio de tratamento pela identidade. Nesse sentido, conclui-se que “[...] o que cura não é o princípio alopático do contrário, mas antes o princípio homeopático do similar [...]” (ESPOSITO, 2011, p. 1258).

Então, neste novo entrelaçamento entre a linguagem médica e o léxico político passa-se para a leitura positiva do que é negativo, e a modernidade vivencia uma alteração semântica da doença: de termos inteiramente negativos, que deveriam ser eliminados a qualquer custo, o conflito, o risco e a ameaça passam a ser tomados por produtivos. Assim, tal qual Maquiavel teria proposto o reforço do poder político por meio de insurgência e tumultos, o saber médico tende a afirmar a positividade de ameaças, toxinas, desde que trabalhadas de forma controlada (ESPOSITO, 2011, p. 124).

Nada representa melhor essa ideia do que o modelo lógico da vacina. Afinal, o que é a vacina senão a injeção, em doses homeopáticas, daquilo que ameaça o corpo são, a fim de estimular a formação de anticorpos e neutralizar, antecipadamente, possíveis doenças? Trata-se de induzir a

\footnotetext{
${ }^{8}$ Tradução livre. No original: “[...] what heals is not the allopathic principle of the contrary, but rather the homeopathic principle of the similar [...]”.
} 
neutralização de um mal (nunca o eliminar) mediante sua inserção controlada - uma inserção por exclusão ou exclusão por inclusão (ESPOSITO, 2011, p. 8).

Como consequência, a preocupação de quem assume essa lógica não está mais em localizar as ameaças externas, organizar forças e enfrentá-las, mas em dosar a quantidade de “veneno” que será internalizada, identificar a dosagem precisa que o corpo necessita para se preparar para ameaças futuras. Assim, tanto no seu aspecto médico, como social, o procedimento de imunização estabelece a conexão antinômica entre proteção e negação da vida, pois o remédio é feito do mesmo "veneno" do qual deve proteger a comunidade, como se para conservar a vida fosse necessário provar a morte. Em síntese, representa a proximidade da vida e da morte, exatamente pelo uso de um mecanismo preservativo/preventivo da vida pela internalização daquilo que a nega. Nas palavras do filósofo italiano, “o vocábulo phármakon contém desde sua origem o duplo significado de < cura $>$ e $<$ veneno $>$ - um veneno como cura, ou uma cura por meio do veneno”9 (ESPOSITO, 2009, p. 115).

Além disso, segundo o autor, a antinomia communitas/immunitas pode servir como chave interpretativa da linguagem da modernidade e de sua biopolítica, que se caracteriza justamente como política de proteção e preservação da vida, mas cuja práticas não só negam e abreviam a vida, como também estão fundadas nessa aporia. Trata-se do "enigma da biopolítica”, que Esposito debate revisitando as ideias de Michel Foucault e reflete sobre como esta política da vida carrega em si o germe da morte que, ao estender a vida de alguns, nega a vida a outros. Para ilustrar tal antinomia, cita o exemplo da guerra humanitária no Afeganistão, iniciada dois meses após o ataque terrorista de 11 de setembro, marcada pelo simultâneo bombardeamento destrutivo e o despejo aéreo de alimentos e medicamentos, evidenciando o paradoxo da defesa da vida pela produção da morte (ESPOSITO, 2008, p. 4).

\footnotetext{
9 “Por otra parte, esta contradicción - esta conexión antinómica entre protección y negación de la vida - está implícita en el procedimiento mismo de la inmunización médica: como es bien sabido, para vacunar a un paciente frente a una enfermedad, se le introduce en el organismo una porción controlada y sostenible de la misma. Esto significa que, en ese caso, la medicina está hecha del mismo veneno del que debe proteger - casi como si para conservar la vida de alguien hubiera que hacerle probar la muerte. Por lo demás, el vocablo phármakon contiene desde su origen el doble significado de $<$ cura $>$ y $<$ veneno $>$ - un veneno como cura, o una cura través del veneno. Sucede como si los modernos procedimientos inmunitarios hubiesen llevado a su máxima intensidad tales contradicciones: cada vez más, la cura se da en la forma de un veneno-medicina. Al llevar esta práctica inmunológica al interior del cuerpo social, se ve la misma paradoja [...]”. Tradução livre: "De outra parte, essa contradição - essa conexão antinômica entre proteção da vida e negação da vida está implícita no procedimento mesmo da imunização médica: como é bem sabido, para vacinar um paciente ante uma enfermidade, se introduz no organismo uma porção controlada e sustentável da mesma. Isso significa que, nesse caso, o remédio é feito do mesmo veneno do qual deve proteger - quase como se para conservar a vida de alguém fosse necessário provar a morte. No mais, o vocábulo phármakon contém desde sua origem o duplo significado de $<$ cura $>$ e $<$ veneno $>-$ um veneno como cura, ou uma cura por meio do veneno. Sucede como se os modernos procedimentos imunitários tivessem levado à máxima intensidade tais contradições: cada vez mais, a cura se dá pela forma de um veneno-remédio. Ao levar essa prática imunológica ao interior do corpo social, vê-se o mesmo paradoxo [...]”.
} 
Então, a proposta do filósofo italiano é a (re)leitura da biopolítica tendo como filtro o paradigma da imunização, isto é, por meio da explicitação do jogo entre comunidade/imunidade, afirmação/negação, vida/morte. Inclusive, a biopolítica, se ligada conceitualmente à dinâmica imunitária, revela sua gênese especificamente moderna. Neste sentido, afirma que categorias políticas muito comuns à modernidade se mostram insertas no paradigma da imunização, trazendo consigo as mencionadas aporias que essa chave interpretativa revela. Deste modo, em que pese sua expressão histórica, essas categorias podem ser interpretadas como formas linguísticas e institucionais adotadas pela lógica imunitária para salvaguardar a vida dos riscos intrínsecos à sua configuração e turbação coletivas. Neste momento, estabelece-se consequentemente uma implicação direta entre vida e política, ainda que não imediata, pois para que a vida se realize efetivamente e seja efetivamente preservada são necessárias várias mediações construídas pelas categorias políticas ${ }^{10}$ (ESPOSITO, 2008, p. 55).

Portanto, pode-se dizer que as categorias políticas modernas exercem um papel de mediação da vida, um papel de imunizar a vida dos riscos e do vazio da comunidade. Tal qual a vacina mal administrada, contudo, a segurança que essas categorias proporcionam insere, de pronto, novos e importantes riscos.

No contexto da biopolítica, o poder soberano é a figura imunitária mais influente e fornece a resposta mais potente ao problema moderno da autoconservação da vida. Já em Hobbes a questão da conservação da vida entra na esfera política e constitui seu objeto predominante (ESPOSITO, 2008, p. 57-63, 2012a, p. 53-82), inclusive à política é confiada a tarefa de salvar a vida. Então, para que seja conservada, a vida precisa renunciar ao que paradoxalmente faz parte de sua potência expansiva e que ao mesmo tempo a coloca em risco de uma retaliação mortal. Para tanto, aciona seu sistema imunitário natural. Contudo, este na maioria das vezes não é suficiente e acaba substituído

\footnotetext{
10 "If that is true, then the most important political categories of modernity are not to be interpreted in their absoluteness, that is, for what they declare themselves to be, and not exclusively on the basis of their historical configuration, but rather as the linguistic and institutional forms adopted by the immunitary logic in order to safeguard life from the risks that derive from its own collective configuration and conflagration. That such a logic expresses itself through historicalconceptual figures show that the modern implication between politics and life is direct but not immediate. In order to be actualizes effectively, life requires a series of mediations constituted precisely by these categories. So that life can be preserved and also develop, therefore, it needs to be ordered by artificial procedures that are capable of saving it from natural risks.” Tradução livre: "Se isso for verdade, então as mais importantes categorias da modernidade não devem ser interpretadas por si, isto é, pelo que elas se declaram ser, tampouco exclusivamente com base em suas configurações históricas, mas antes como as formas linguísticas e institucionais adotadas pela lógica imunitária a fim de salvaguardar a vida dos riscos que derivam de sua configuração e conflagração coletivas. O fato de que essa lógica se expressa por meio de figuras histórico-conceituais mostra que a moderna implicação entre vida e política é direta, mas não imediata. Para que se realize efetivamente, a vida requer uma série de mediações constituídas precisamente por essas categorias. Para que a vida possa ser preservada e se desenvolver, portanto, ela necessita ser ordenada por procedimentos artificiais que sejam capazes de salvá-la dos riscos naturais.”
} 
por uma imunidade induzida e artificial, que se encontra fora do corpo individual, simultaneamente cumprindo e negando a imunidade natural, de forma a conter sua intensidade perigosa. Note-se que justamente este dispositivo metaimunitário é a soberania (ESPOSITO, 2008, p. 59).

Consequentemente, segundo o filósofo italiano a soberania aparece como o mecanismo artificial criador de um vácuo ao redor de cada indivíduo. Não mais relacionados entre si, não mais em comunidade, os indivíduos neutralizam o medo do vazio. Relacionam-se apenas com o soberano, o qual é encarregado da preservação da vida, mas que, paradoxalmente, é o único a manter o natural direito de findá-la.

Além disso, segundo a interpretação espositiana de Hobbes, a soberania também pode ser vista como um resto de violência não mediável pelo dispositivo imunitário porque foi produzida por ele próprio. Se por um lado a soberania tem por finalidade neutralizar o conflito, por outro não pode eliminá-lo, mas deve integrá-lo, no organismo imunizado, como antígeno necessário à formação permanente de anticorpos (ESPOSITO, 2008, p. 61-62).

Nesse quadro, a propriedade nada mais representaria do que a multiplicação em cada indivíduo da lógica da soberania (ESPOSITO, 2008, p. 63), numa resposta imunitária à indistinção, na comunidade, entre "meu” e "seu”. Por seu turno, a liberdade moderna asseguraria "o indivíduo contra a interferência dos outros mediante sua subordinação voluntária a uma ordem mais poderosa que o garanta”, tornando ele próprio igualmente soberano no interior de sua individualidade. Em síntese, os indivíduos seriam “[...] obrigados a obedecer ao soberano porque livres de mandar em si próprios e vice-versa.”11 (ESPOSITO, 2008, p. 72).

Ressalta-se que a vantagem da leitura de Esposito sobre as teses contratualistas está em sua capacidade de evidenciar as aporias intrínsecas às mediações modernas e acaba por responder ao “enigma da biopolítica”. Ao avaliar essas categorias (especialmente soberania, propriedade e liberdade), demonstra que não apenas a comunidade está sempre em risco de se autodestruir (já que, no fundo, a imunização é a proteção pela negação), como os mecanismos criados pela modernidade mostram-se contraditórios ao próprio objetivo a que se propõem, qual seja, a preservação e a prolongação da vida. Nas palavras do autor, "se à filosofia política moderna é dada a tarefa de proteção da vida, a qual é sempre determinada negativamente, então as categorias políticas

\footnotetext{
11 Tradução livre. No original: "On the other hand, such subjects are themselves conceives as equally sovereign within their own individuality - obliged to the sovereign because they are free to command themselves and vice versa. [...] In the most general terms, modern liberty is that which insures the individual against the interference of others through the voluntary subordination to a more powerful order that guarantees it”.
} 
organizadas para expressá-la acabarão por ricochetear contra seus próprios devidos sentidos, retorcendo-se sobre si."12 (ESPOSITO, 2008, p. 56).

Surgem aqui dois paralelos interessantes. De um lado, as deficiências imunológicas, especialmente bem representadas na aids, que muito frequentemente se utilizam do mecanismo imunológico humano para se espalharem. Nesse caso, trata-se de um uso, por um agente externo, de um mecanismo de defesa interno. De outro, de forma ainda mais paradoxal, as doenças autoimunes, definidas basicamente como uma reversão do próprio sistema imunológico contra o organismo que deveria ser preservado. Não há uma falha na imunização, mas uma exacerbação, uma reversão sobre si mesmo. E o que mais impressiona é que nem sequer havia uma ameaça externa contra a qual reagir, tratando-se de uma ameaça criada pelo organismo (ESPOSITO, 2011, p. 159-165).

Esposito explica que a reversão sobre si mesmo, decorrente de deficiências imunológicas e especialmente de doenças autoimunes, representa na verdade “o impulso natural de todo sistema imunitário” (ESPOSITO, 2011, p. 65) ${ }^{13}$, que carrega uma tendência ínsita para a reversão da biopolítica (política da vida) em tanatopolítica (política sobre a vida), esta mais bem representada pelos dispositivos nazistas da absoluta normatização da vida, do duplo fechamento do corpo e da suspensão antecipada do nascimento (ESPOSITO, 2008, p. 138-145).

O evento nazista não é tomado aleatoriamente, pois traduz a lógica imunitária levada ao paroxismo, revelando o caráter inevitavelmente aporético de toda a modernidade. Isto é, mantendose o uso das categorias de mediação insertas nessa lógica de afirmação pela negação ou de inclusão pela exclusão, não é crível esperar por resultados diversos. As práticas biopolíticas concretas relatadas no início de Bíos são mais do que prova da força e atualidade do argumento (ESPOSITO, 2008, p. 37).

\footnotetext{
12 Tradução livre. No original: "If modern political philosophy is given the task of protecting life, which is always determined negatively, then the political categories organized to express it will end up rebounding against their own proper meanings, twisting against themselves. And that notwithstanding their specific contents: the pretense of responding to an immediacy - the question of conservatio vitae - is contradictory to the mediations, which are precisely the concepts of sovereignty, property, and liberty”. Tradução livre: "Se à filosofia política moderna é dada a tarefa de proteção da vida, a qual é sempre determinada negativamente, então as categorias políticas organizadas para expressá-la acabarão por ricochetear contra seus próprios devidos sentidos, retorcendo-se sobre si. E isso desconsiderando seus conteúdos específicos: a pretensão de responder a uma imediação - a questão da conservatio vitae - é contraditória às mediações, que são precisamente os conceitos de soberania, propriedade e liberdade”.

13 "Here we arrive at the key point of the argument: the destructive rebellion against the self is not a temporary dysfunction, but the natural impulse of every immune system". Ainda: “As for this aporetic consequence fully revealed by the figure of autoimmunity, we might ask, was it not already implicit in the principle of homeopathic correspondence between treatment and poison?” Tradução livre: “Aqui nós chegamos ao ponto-chave do argumento: a rebelião destruidora contra si não é uma disfunção temporária, mas o impulso natural de todo sistema imunitário”. Ainda: “Quanto a esta consequência aporética totalmente revelada pela figura de autoimunidade, poderíamos perguntar, isso já não estava implícito no princípio da correspondência homeopática entre tratamento e veneno?”
} 
Neste caso, a preocupação de Esposito, constatada a inevitabilidade da reversão autoimune das categorias modernas, é pensar uma biopolítica afirmativa, que negue os próprios pressupostos da lógica imunitária. Aqui, seus argumentos se tornam, compreensivelmente, menos analíticos do que no restante de suas obras. Não obstante, desde o exemplo do cyborg e do implante, passando pela releitura do acontecimento do nascimento (ESPOSITO, 2011, p. 165-177), até a tentativa de reversão afirmativa dos dispositivos nazistas - repensar vida, corpo e nascimento - (ESPOSITO, 2008, p. 157194), uma ideia se mostra recorrente: parece fundamental uma reinterpretação não excludente da imunidade, situação na qual comunidade e imunidade se tornam indistinguíveis, ou seja, pensar em direção à diferença e à relação “eu” e “outro”.

Em que pese a experiência nazista seja um exemplo contundente e extremo da lógica imunitária da modernidade, esta funciona normalmente por meio de dispositivos um pouco mais sutis e dissimulados pela forma jurídica, tal como a punição legal.

\section{IMUNIZAÇÃO E PENA}

A pena pode ser definida, na perspectiva contratualista, como a imposição intencional e autorizada de sofrimento ou dor a um indivíduo, em razão de um ato (suposto ou real) que tenha ofendido uma regra prevista por um sistema legal ${ }^{14}$.

Essa definição se afasta do legalismo com que juristas geralmente trabalham - pressupondo a pena como "consequência jurídica de um delito" - para apontar diretamente para o elemento problemático da pena, a dor imposta intencionalmente e autorizada pelo sistema legal.

Ressalta, portanto, a necessidade de solucionar o que Boonin enunciou como "problema moral da pena”, fundado no fato de que a punição legal implica tratar os que violam a lei de maneiras que são vedadas para o tratamento daqueles que a obedecem. Diz respeito ao desafio de tornar moralmente permissível que o Estado trate a pessoa que violou a lei justa e razoável de maneiras que em outras circunstâncias seriam vedadas pela mesma lei. Nas palavras do autor, o problema da pena pode ser traduzido nas seguintes questões:

Como pode o fato de que a pessoa violou uma lei justa e razoável tornar moralmente permissível que o Estado a trate de formas que, noutras circunstâncias, seriam vedadas? Como pode a linha entre aqueles que violam essas leis e aqueles que não o fazem ser moralmente relevante, na maneira que a prática da pena exige? (BOONIN, 2008, p. 1) ${ }^{15}$.

\footnotetext{
${ }^{14}$ Comparar com: Boonin (2008, p. 1-28); Lacey (1988, p. 5-12); Hart (2008, p. 1-27); Nino (1980, p. 298-208).

15 Tradução livre. No original: "How can the fact that a person has broken a just and reasonable law render it morally permissible for the state to treat him in ways that would otherwise be impermissible? How can the line between those
} 
Nesse sentido, para responder ao chamado problema da pena e suas implicações morais, cabe às teorias da pena fornecer razões consistentes que justifiquem a linha moralmente relevante traçada entre inocentes e culpados, que autoriza a tratar os últimos de maneira diversa dos primeiros ${ }^{16}$.

Além disso, a definição de pena apresentada, ao evidenciar o “problema da pena” e a essencialidade do elemento dor (ou sofrimento), busca chamar a atenção para a distinção que se intenta estabelecer entre pena e vingança.

Ao contrário da vingança ou da violência gratuita, a pena é a inflição de dor autorizada. Essa autorização, contudo, não interfere na natureza do ato que se pratica, mas tão somente na transferência de responsabilidade de decidir - do sujeito diretamente envolvido para, mediante um mecanismo de mediação, uma estrutura previamente criada para tal fim. Nos termos de Ricoeur (2008, p. 251-260), trata-se de estabelecer uma distância entre ação e resposta aflitiva. Mais precisamente, por meio da instituição de um corpo político com o papel de decidir sobre a culpa e a inocência, bem como com o papel de executar penas, pretende-se "transferir os conflitos do nível da violência para o nível da linguagem e do discurso" (RICOEUR, 2008, p. 255).

Ocorre que, no momento decisivo, como na sentença e na execução da pena, um ato de força e violência mantém-se insuprimível: ainda que por meio dos discursos de justificação da pena se repute a pena justa e merecida, é preciso reconhecer que não se elimina o ato violento.

Em Immunitas, Esposito (2011, p. 21-51) trabalha com termos muito semelhantes. Contudo, para ele, a manutenção do ato violento não se limita à imposição da pena, mas sim configura uma característica intrínseca a todo o direito, que funcionaria dentro da lógica imunitária, com todas as aporias já apresentadas. A essencialidade da dor na pena e o desconforto moral que ela provoca apenas ressaltam o argumento.

Assim, o autor explica que a função imunizante que o direito exerce sobre a comunidade é óbvia, na medida em que foi prescrito para preservar a convivência pacífica entre as pessoas naturalmente expostas ao risco destrutivo. Portanto, mesmo antes de ser traduzido em Código, o direito é necessário para a manutenção da vida da comunidade e funciona como o sistema imunitário para o organismo, garantindo por meio de um método indireto, retorcido e perverso a sobrevivência

who break such laws and those who do not be morally relevant in the way that the practice of punishment requires it to be? This is the problem of punishment.".

${ }^{16}$ É muito comum a confusão entre justificação da pena e a atribuição de funções à prática. É errado afirmar, por exemplo, que Kant não admite quaisquer efeitos da pena. O que Kant não admite é que a pena se justifique com base nesses efeitos, mas em nenhum momento refuta eventuais "benefícios” concretamente auferíveis. Ver: Clarke (1982). Ainda, é preciso atenção para com a distinção entre o discurso descritivo que pretende apreender a prática de apenar e o discurso normativo que busca justificá-la. 
desta comunidade em uma situação de risco vital. Noutras palavras, a imunidade criada pelo direito não opera afirmativamente para atingir seu objetivo de manutenção da vida, pois utiliza um elemento composto pela mesma substância contra a qual ele foi estruturado para agir ${ }^{17}$ (ESPOSITO, 2011, p. 21).

O direito, nessa leitura, não reage a uma ameaça externa, mas à ameaça interna representada pela própria coexistência em comunidade; estabelece mecanismos de mediação que, como dito, assumem a lógica imunitária da funcionalidade do conflito, da negação.

Como Esposito (2011, p. 36-45) alerta, a partir da reflexão de René Girard, o direito nunca operou pela supressão ou pela eliminação da violência. Ao contrário, opera mediante a estratégia da alocação, da estratégia topográfica: primeiro, a violência é internalizada, para, depois, ser alocada num espaço teatral onde é neutralizada. Isto é, “em vez de simplesmente incorporar o que está fora de si (vale dizer, a violência), o direito se coloca numa dimensão diversa ao corpo social no qual perpetra a violência”18 (ESPOSITO, 2011, p. 41).

Então, com base em um mecanismo de apropriação, a comunidade formula uma estrutura que torna funcional exatamente aquilo do que quer se proteger, alocando esse elemento negativo, a violência, em um espaço controlado no qual a questão central passa a ser de dosagem.

Aliás, essa explicação pode ser encontrada nas clássicas justificativas iluministas para a existência do direito penal e do processo penal, tal como se verifica na obra do contemporâneo Ferrajoli, que justifica a existência da pena não só por prevenir delitos futuros, mas pela sua

\footnotetext{
17 "The immune function that the law performs for the community is immediately obvious, and as such is universally recognized even outside the legal literature. From the outset, it was prescribed to preserve peaceful cohabitation among people naturally exposed to the risk of destructive conflict. Even before being put into codified forms, therefore, law is necessary to the very life of the community. This is the primal, radical sense of the immunizing role it performs: just as the immune system functions for the human organism, law ensures the survival of the community in a life-threatening situation [...]. The immunity created by law for the community, just like the immunity created by the human body, does not operate directly and affirmatively, so to speak, in attaining its goal. On the contrary, it is forced to adopt an indirect, twisted, or even, literally, perverse method to reach its objective, one that is only attainable through an instrument that contradicts it [...]. This is because it contains an element of the same substance it is intended to defend against”. Tradução livre: “A função imunizante que o direito exerce para a comunidade é imediatamente óbvia, sendo como tal universalmente reconhecida mesmo para além da literatura jurídica. Desde a origem, o direito foi prescrito para preservar a coabitação pacífica entre pessoas naturalmente expostas ao risco destrutivo. Mesmo antes de ser posto em formas codificadas, portanto, o direito é necessário para a própria vida da comunidade. Esse é o primeiro, radical sentido da função imunizante que ele exerce: tal qual funciona o sistema imunitário para o organismo humano, o direito garante a sobrevivência da comunidade em uma situação de risco vital [...]. A imunidade criada pelo direito para a comunidade, assim como a imunidade criada pelo corpo humano, não opera direta ou afirmativamente para atingir seu objetivo, por assim dizer. Ao contrário, ela é forçada a adotar um método indireto, retorcido ou mesmo, literalmente, perverso para atingir seu objetivo, o qual só é apreensível por meio de um instrumento que o contradiga [...]. Isso se dá porque ele contém um elemento composto da mesma substância contra a qual ele foi desenhado para agir”.

18 Tradução livre. No original: "Rather than simply incorporate what lies outside itself (namely violence) the law places itself in a different dimension from the social body onto which it perpetrates the violence”.
} 
possibilidade de controle da violência a ser perpetrada contra o criminoso (1995, p. 247-320). Sem esse aparato de contenção, é pressuposta uma violência sem limites, de toda a comunidade contra o criminoso. Inclusive, os escritos de Ferrajoli ressaltam expressamente que a marca da transição dos castigos medievais para as penas da modernidade, mediadas pelo direito estatal, é justamente o fato de que a “ [...] violência infligida com a pena é sempre programada, consciente, organizada, por muitos contra um.”"19 (FERRAJOLI, 1995, p. 386).

Em suma, de acordo com esse raciocínio, uma lógica sacrifical se mostra inescapável, ou seja, todos menos um; um no lugar de todos (ESPOSITO, 2011, p. 39). Para se imunizar da violência natural, a comunidade estabelece que a violência só será permitida contra aquele que viola as regras estabelecidas pelo mecanismo imunitário.

Assim como pensado pela antropologia filosófica quanto à ideia de compensação (ESPOSITO, 2011, p. 82-23), a pena não retira ou elimina o dano ou o mal causado pela transgressão. Ao contrário, a cura é pela evidência dessa transgressão, por torná-la visível a toda a comunidade. Novamente, trata-se de uma positivação daquilo que é negativo.

Ao estar inserta na lógica imunitária do direito, a pena está prenhe das contradições antes expostas. Seguindo a tendência geral da imunização, é sua consequência inevitável a extrapolação, na forma da crise autoimune. Como mecanismo de proteção da vida pela incorporação de sua negação, também o direito tende ao paroxismo, justamente pelo fato de que mesmo uma pena equitativa (justa) continua sendo punição, infligindo um sofrimento. Nesse sentido, ainda que passe por uma mediação, prorrogada e filtrada por todo o procedimento judicial, a punição não deixa de abrir espaço para um espírito de vingança (RICOUER, 2008, p. 258).

Nesse caso, o direito e a pena, esta como demonstração mais bem-acabada de seu funcionamento, tendem a deixar de cumprir o objetivo para o qual foram desenhados - como todas as categorias modernas, são mediações contraditórias ao fim imediato de proteção da vida (ESPOSITO, 2008, p. 56).

Ademais, de forma mais dramática, é preciso lembrar que o mecanismo de segurança da imunização, quando ameaçado, tende a adaptar a percepção do risco, incluindo a possibilidade de gerá-lo. O resultado final não pode deixar de ser um mecanismo protetivo mais perigoso do que o próprio risco contra o qual foi, na origem, criado (ESPOSITO, 2011, p. 5).

Em resumo, a relação que aqui se desenha, entre a punição legal e o paradigma imunitário, afeta diretamente a pretensão de justificação da pena, na medida em que exige a apresentação de

\footnotetext{
${ }^{19}$ Tradução livre. No original: “[...] la violencia ingligida con la pena es siempre programada, consciente, organizada por muchos contra uno.”.
} 
razões coerentes para afirmar que a pena é compatível com um determinado modelo de comunidade política (com especial dificuldade para o liberalismo político ${ }^{20}$ ) e estabelece a preocupação com a sempre iminente reversão em crise autoimune.

Assim, a teoria que pretende justificar a pena deve fornecer razões para acreditarmos que a dosagem de dor inerente à punição legal será sempre mantida em níveis aceitáveis. Deverá também explicar como é possível bloquear a tendência autodestrutiva da comunidade, mediante o estabelecimento de um mecanismo fundado na positivação do que é negativo, o que sem dúvida fica muito mais difícil quando se trata de pena de morte, ainda aplicada contemporaneamente em sistemas de justiça criminal.

Por certo, nada impede que se neguem as implicações de tais questões, refutando o próprio raciocínio geral de Roberto Esposito, porém nesse caso será necessário o engajamento num debate afeto à filosofia política, deslocando a reflexão para os princípios que devem limitar o exercício do poder estatal, algo imprescindível para as tentativas de justificação da pena e precariamente praticado.

Ressalte-se que as ideias de Esposito dão robustez teórica a uma trilha de crítica ao sistema penal que há muito percebe as contradições aqui tratadas. Neste sentido, reconhecer que, tanto o fracasso empírico das ditas funções da pena, quanto a percepção de que a promessa de controle da violência sofre de uma fragilidade lógica intransponível, aparece como o ponto de partida de propostas que pensam a possibilidade de caminhos alternativos.

Veja-se por todos Eligio Resta, que, ao fazer uma releitura crítica do que ele chama de direito vivente (o direito permeado pela biopolítica), parte do pressuposto de que existe uma cumplicidade dos contrários própria da violência, da lei, da escritura, na qual se encontra uma ambivalência que faz algo, porque e quando faz o oposto, isto é, adoenta e adoenta curando, libera vinculando e vincula liberando, pacifica usando a violência e usa a violência pacificando. Além disso, Resta acentua que tais dispositivos da modernidade, sobretudo a lei e o direito, funcionam tal qual um pharmakón, que na acepção grega representa o vocábulo mais significativo para traduzir a ambiguidade paradoxal, pois encerra o veneno e o antídoto, a cura e a doença, o carrasco e a vítima, a memória e o esquecimento, a presença e a ausência, a racionalidade e a irracionalidade (RESTA, 2008, p. 86). Esta análise servirá para fundamentar sua proposta de um outro direito, fraterno, distante das dicotomias, do binômio amigo/inimigo.

O mesmo caminho de pensamento se encontra na proposta de um direito pós-identitário, que pretende superar o direito marcado pelo binômio de gênero masculino/feminino, que assegura direitos

\footnotetext{
${ }^{20}$ Ver, sobre a dificuldade de se justificar a pena dentro de um framework de princípios liberais: Matravers (2013); Metz (2007); Brubaker (1988).
} 
apenas àqueles que se encaixam no padrão de normalidade de homem e mulher definidos pela biologia e pelas práticas sociais. Tal tentativa parte justamente da crítica ao direito da modernidade, que assegura direitos aos mais vulneráveis e busca conter a violência contra eles pelo uso da própria violência. Ocorre que esses instrumentos de proteção reafirmam os padrões identitários de gênero que geram a violência a qual o próprio direito pretende combater. Além disso, ao criminalizar a violência de gênero, o Estado torna as identidades de gênero vulneráveis ainda mais débeis, incapazes de se defender e carecedoras da intervenção estatal violenta, armada, masculina (BORGES; BORTOLOZZI JR., 2016).

Em suma, o esforço empreendido neste ensaio não se direciona a apontar erros práticos na aplicação concreta dos pressupostos do sistema penal, mas busca refletir sobre as aporias desses pressupostos e imaginar alternativas que consigam delas escapar, dentre elas o que se tem chamado de justiça alternativa.

\section{JUSTIÇA RESTAURATIVA E A IDEIA DE COMUNIDADE}

Tem-se consciência de que o termo “justiça restaurativa” é capaz de abarcar concepções teóricas e propostas práticas com direções muito diversas ${ }^{21}$, quando não abertamente contrapostas, porém acredita-se que algumas percepções em comum sobre o sistema penal podem ser traçadas a partir das várias teorias sobre o tema (MORRIS, 2005).

Dentre essas percepções comuns, identifica-se que para os restaurativistas a punição legal parece não responsabilizar efetivamente o causador do dano; por esse motivo a imposição intencional de dor não transmitiria ou comunicaria qualquer sentido, assimilando-se a uma violência gratuita ${ }^{22}$. Ademais, pouca ou nenhuma atenção seria dada à vítima do dano, cuja participação no processo punitivo seria praticamente nula. Nesse contexto, a comunidade diretamente afetada pela situação definida como crime também não teria meios de comunicar suas impressões tanto à vítima, quanto ao causador do dano, assim o dano causado também não seria devidamente enfrentado, sendo sua reparação (meramente pecuniária) relegada a um efeito secundário da condenação. Por fim, toda a situação seria tratada como uma questão de Estado, entidade que responderia com seus profissionais previamente designados, que dariam respostas também previamente designadas (ACHUTTI, 2014).

\footnotetext{
${ }^{21}$ Para uma boa introdução ao tema, com a apresentação dessas diversas abordagens agrupadas sob o nome “justiça restaurativa”: Sica (2007).

${ }^{22}$ Essa é, aliás, uma preocupação constante por parte de teóricos que creem na possibilidade de justificação, em abstrato, da pena. Ver, pela relevância dos autores: Hampton (1984); Duff (2001); Feinberg (1965).
} 
Como há muito Christie (1977) resumiu, o sistema penal estaria calcado no roubo do conflito por parte do Estado.

Essas percepções não são nada surpreendentes se levada em conta a lógica imunitária do direito. Ao se apropriar produtivamente daquilo que constitui sua própria negação, a comunidade, por meio do sistema penal, está destinada a não enfrentar as situações que define como crimes. A resposta mediante o sistema penal é sempre uma resposta mediada por mecanismos que distanciam os sujeitos envolvidos - essa distância, aliás, está na própria pretensão, nunca realizada, de dissociação entre justiça e vingança (RICOEUR, 2008).

Ainda que em muitos casos seu motor principal sejam insatisfações empíricas com o funcionamento do sistema penal, propostas de práticas restaurativas parecem compartilhar a percepção de que, no fundo, toda a estrutura punitiva é calcada numa "promessa perenemente vã " (GIAMBERARDINO, 2015, p. 107).

Com Howard Zehr (2015), pode-se afirmar que a noção de comunidade é central para a pretensão de estabelecer formas de resposta diversas daquela oferecida pelo sistema de justiça criminal. A comunidade é eleita como uma das três dimensões fundamentais das práticas restaurativas. Ao lado da vítima e do ofensor, é ela igualmente responsável pelos rumos de enfrentamento da situação problemática.

Normativamente, nas práticas restaurativas é formulada como positiva a própria participação dos sujeitos diretamente envolvidos no conflito, sem um detalhamento prévio das implicações e resultados desse processo (CHRISTIE, 1977, p. 6-10; MORRIS, 2005, p. 442). É inegável, outrossim, que inúmeros estudos empíricos vêm reforçando o otimismo característico dos textos de teóricos da justiça restaurativa ${ }^{23}$.

Se o esforço em fomentar a participação dos sujeitos diretamente envolvidos no conflito representa um dos pontos mais fortes da justiça restaurativa, por potencialmente apontar para uma fuga aos mecanismos assépticos do sistema penal, é justamente no central conceito de comunidade que está a maior fraqueza teórica dessas propostas.

Alerta-se que trabalhar com uma noção de comunidade não é exclusividade de teóricos da justiça restaurativa. Para tomar um dos mais consistentes autores que mantém a pretensão de justificar a pena, talvez a maior preocupação de R. A. Duff (2001) seja garantir que por meio da prática aflitiva da pena a comunidade transmita, como processo comunicativo, valores que considera essenciais. Por

\footnotetext{
${ }^{23}$ Ver os dados reunidos em SHAPLAND; ROBINSON; SORSBY (2011).
} 
outro lado, Nicola Lacey (1988) procura desvincular a justificação da pena do quadro de princípios do liberalismo político, para alocá-las sob abrigo de princípios afetos ao chamado comunitarismo.

Embora essas propostas se distanciem da justiça restaurativa, principalmente, pelo tratamento em relação à pena (pensada como imposição intencional de dor), o arcabouço valorativo em que se apoiam é bastante semelhante. Para além de alguma relação que possa ser estabelecida entre maior participação dos sujeitos envolvidos no conflito e ideais da tradição política republicana (DZUR, 2011, 2012; DZUR, MIRCHANDANI, 2007), o conceito de comunidade é duramente marcado pelo essencialismo que tanto preocupa Roberto Esposito (2009, p. 25-44, 2012a, p. 21-49).

Como lembra Rosenblatt (2014), não é muito claro o que teóricos da justiça restaurativa têm em mente quando se referem a comunidade. Inclusive, muitos questionamentos podem ser feitos tanto à pressuposição de que a participação da comunidade é “boa em si”, quanto à forma como concretizar essa participação. Não se atentar para a falta mínima de igualdade material entre os sujeitos mais afetados pelo sistema penal, para a possibilidade de não só manter, mas acentuar preconceitos e desigualdades ou, especialmente, para a inserção de um elemento aproximativo em sociedades marcadas pelo distanciamento entre os sujeitos pode acabar por relegar as promessas da justiça restaurativa ao mesmo fracasso de outras formas de mediação antes tentadas ${ }^{24}$.

Corre-se o risco de "romantizar” a comunidade e reproduzir a violência das desigualdades sociais, inerentes à maioria das sociedades contemporâneas, reforçando desta forma o uso da violência para combater a violência, a manutenção da vida pela destruição de outras vidas. Ademais, muitas experiências restaurativas incorrem em equívocos no envolvimento da comunidade na resolução dos conflitos, aplicando as fórmulas imunitárias do direito moderno ${ }^{25}$.

Certamente, os restaurativistas podem responder a todas essas objeções com argumentos simples, que contêm boa dose de acerto. Podem afirmar que, diante do gritante fracasso empírico do

\footnotetext{
${ }^{24}$ Pense-se, por exemplo, no funcionamento dos Juizados Especiais Criminais (ALMEIDA, 2014) ou nas violentas experiências de transposição das ideias de polícia comunitária na realidade brasileira.

25 “O fato é que a 'romantização da comunidade’ (McEvoy e Mika, 2002) é perigosa. É perigoso presumir que existe 'uma coisa boa' lá fora (do sistema de justiça criminal) chamada 'comunidade', marcada por relações de equidade, onde as pessoas são amigáveis e bem intencionadas, e à qual a vítima e o infrator podem ser reintegrados sem maiores esforços (Bauman, 2001). E o perigo é ‘a suposição, ínsita nos apelos à comunidade, de que o status quo é justo’ (Weisberg, 2003, 370) - quando, na prática, ao objetivar a restauração do status quo, as intervenções restaurativas podem acabar reproduzindo as diferenças de poder e status pré-existentes na comunidade (Delgado, 2000). Tem mais. Ao invés de presumir que o maior envolvimento da comunidade leva necessariamente a processos de justiça menos formais e menos profissionalizados, os entusiastas da justiça restaurativa devem estar atentos ao perigo de simplesmente replicar um sistema formal de justiça no seio das comunidades (Bartkowiak e Jaccoud, 2008). Com efeito, o envolvimento da comunidade em processos restaurativos pode acabar se tornando 'uma ilusão a fim de permitir mais controle social' e 'uma forma das instituições governamentais recuperarem sua justificação e sua legitimidade perdidas' (Bartkowiak e Jaccoud, 2008, p. 229)” (ROSENBLATT, 2014, p. 58).
} 
sistema penal, qualquer tipo de proposta alternativa é comparativamente superior. Neste sentido, para tomar emprestado o raciocínio de Alisson Morris (2005, p. 444-445, 447-448), por exemplo, sustentar que a abertura para os procedimentos informais das práticas restaurativas erodiria garantias individuais é no mínimo irônico se considerado o concreto funcionamento do sistema penal. Da mesma forma, alegar que as propostas restaurativas "trivializariam” os danos causados por crimes pode ser rebatido com um simples olhar sobre a efetiva ausência de responsabilização moral resultante da condenação criminal (GIAMBERARDINO, 2015, p. 139-140), sendo a ligação entre a pena e o dano causado completamente rompida durante o processo penal. Em outros termos, não seria difícil banalizar um processo que há muito perdeu seu potencial comunicativo (DUFF, 2001, p. 88$96)^{26}$.

Entretanto, deve-se admitir que essa ordem de argumentos, embora importantes, não enfrenta o âmago da questão. Para além de comparações com o sistema penal, é fundamental que teóricos da justiça restaurativa sejam capazes de fornecer um embasamento coerente e robusto, sob pena de, na tentativa de escaparem ao mecanismo imunitário do sistema penal, elaborarem uma noção de comunidade ainda mais imunitária.

Ao justificar seu interesse pela comunidade, Esposito (2012a, p. 21-22) afirma que não faltam filosofias expressamente dirigidas à comunidade. Carregam, porém, por trabalharem com léxico político-filosófico da modernidade, “insustentáveis distorções” ou mesmo "perversões” do conceito. Isso porque todas trabalham a comunidade como uma propriedade, como algo que deve ser tomado e protegido pelos indivíduos, o que vai de encontro ao caráter im-próprio do que é comum, tal como afirmado.

Deste modo, resta clara a dificuldade de se pensar a ideia de comunidade e de como isso afeta o direito e principalmente o julgar com base no direito, até porque como afirmou Hannah Arendt (1992, p. 7-77), ao interpretar a filosofia de Kant, a própria faculdade de julgar é impossível para além do estar-em-comum. Neste aspecto Esposito (2012a, p. 112-145; 2009, p. 25-44) demonstra quão problemática é a pretensão de concretizar esse espaço e riscos de se manter a comunidade com base no que pode destruí-la.

Então, o que se busca com o presente ensaio talvez se reduza a uma advertência metodológica aos que pensam em alternativas para o sistema penal, pois pretende-se alertar que não

\footnotetext{
${ }^{26}$ Não à toa, perspectivas sérias que admitem a legitimidade em abstrato da pena tendem a fornecer um olhar crítico do potencial de efetiva responsabilização dessa medida estatal. Nesse sentido, uma teoria normativa do "calling to account”, mesmo na perspectiva liberal, mostra-se difícil. Para uma excelente abordagem do assunto: Clark (2006, p. 83-98); Duff et al. (2006, p. 1-14).
} 
se pode tratar desta questão com ingenuidade, como parecem fazer as filosofias que veem no compartilhamento de certas características comuns o sentido de comunidade. O risco de tais manifestações recaírem em princípios racistas e xenofóbicos é perene - daí ser possível chamá-las de novos mecanismos imunitários. E o que isso ocasiona é a absoluta indistinção dos opostos (guerra/paz; vida/morte; segurança/risco), cujo melhor exemplo concreto é o uso indiscriminado do discurso dos direitos humanos para, em termos diretos, causar a morte (ESPOSITO, 2008, p. 148149).

Atestar a dificuldade do conceito de comunidade não pode representar simplesmente a recusa a dar um passo para o novo. Ao contrário, deve servir de motivação para o necessário processo criativo de pensar alternativas.

Comunidade não pressupõe imunização (ESPOSITO, 2011, p. 100). Isso não significa que formas de mediação, de subjetivação não sejam necessárias. Significa que a preocupação da política com a vida pode ser pensada de forma não destrutiva, para fora da lógica imunitária. O primeiro passo para tanto é aceitar a contradição dos mecanismos criados pela modernidade, jamais insistir em seu pretenso mau funcionamento, isto é, crer que em algum momento essa mesma abordagem destrutiva será contida.

O impactante relato da luta do feto com o organismo da mãe (ESPOSITO, 2011, p. 165-177) sugere que a busca pelo sentido de imunidade deve ser direcionada à diferença e às complexas relações entre “eu” e “outro”: “Dessa perspectiva, nada resta da incompatibilidade entre eu e outro. O outro é a forma que o eu toma onde o interno cruza com o externo, o próprio com o comum, a imunidade com a comunidade"27.

Se isso tem algo a dizer acerca do sistema penal, é a imprescindibilidade de pensar o diferente. Não como uma forma de protegê-lo, imunizá-lo, mas sim como algo que também constitui o eu, algo que pode constituir o sentido mais profundo de comunidade. Neste sentido, afirma Judith Butler (2015, p. 69), que em vez de julgarmos o outro, de abandonarmos os condenados, de lhes infligir violência ética, devemos interpelá-los, fornecer-lhes condição que sustente condutas éticas. Talvez este seja o caminho para impedir a reversão da biopolítica em tanatopolítica.

\footnotetext{
${ }^{27}$ Tradução livre. No original: "From this perspective, nothing remains of the incompatibility between self and other. The other is the form the self takes where inside intersects with outside, the proper with the common, immunity with community”.
} 


\section{CONCLUSÃO}

O objetivo do presente ensaio, como anunciado, foi chamar a atenção para algumas das direções que as chaves interpretativas oferecidas pelas ideias de Roberto Esposito poderiam apresentar para refletir sobre o sistema penal.

Neste sentido, entende-se que a leitura da modernidade por intermédio do paradigma imunitário abre a possibilidade de ler o direito e a pena de uma perspectiva, se não nova, ao menos mais bem embasada. O esforço dispensado por pesquisadores sérios à justificação da pena revela com muita clareza a dificuldade de compatibilizar essa prática, por definição aflitiva, com ideais democráticos. Então, o que a exploração da lógica imunitária parece possibilitar é explicar o motivo pelo qual uma prática tão problemática é tão difundida e incorporada nas sociedades modernas.

De outro lado, ao proporem uma fuga à lógica desastrosa do sistema penal, os restaurativistas sabem que correm riscos e, por trabalharem profundamente com a questão da comunidade, a obra de Esposito também pode lhes fornecer uma fonte de questionamentos e, principalmente, um sinal de alerta para que suas propostas não caiam no mesmo tipo de contradições inerentes ao paradigma da imunização.

\section{REFERÊNCIAS}

ACHUTTI, Daniel. Abolicionismo penal e justiça restaurativa: do idealismo ao realismo político criminal. Revista Direitos e Garantias Fundamentais, Vitória, v. 15, n. 1, p. 33-69, jan./jun. 2014.

ALMEIDA, Vera Ribeiro de. Transação penal e penas alternativas: uma pesquisa empírica em Juizados Especiais Criminais no Rio de Janeiro. Rio de Janeiro: Lumen Juris, 2014.

ARENDT, Hannah. Lectures on Kant's political philosophy. Chicago: The University of Chicago Press, 1992.

BOONIN, David. The problem of punishment. New York: Cambridge University Press, 2008.

BORGES, Clara Maria Roman; BORTOLOZZI JR., Flavio. Uma crítica foucaultiana à criminalização do feminicídio: reflexões sobre um direito pós-identitário para a diminuição da violência de gênero. Revista da Faculdade de Direito UFPR, Curitiba, PR, Brasil, v. 61, n. 3, p. 323-344, dez. 2016.

BRUBAKER, S. C. Can liberals punish? The American Political Science Review, v. 82, n. 3, p. 821-236, 1988.

BUTLER, Judith. Relatar a si mesmo: crítica da violência ética. Tradução Rogério Bettoni. Belo Horizonte: Autêntica, 2015. 
CHRISTIE, Niels. Conflicts as Property. British Journal of Criminology, v.17, p. 1-15, 1977.

CLARK, Sherman J. Who do you Think you Are? The Criminal Trial and Community Character. In: The Trial on Trial. Vl. II. Judgement and Calling to Account. Portland: Hart Publishing, 2006, p. 83-98.

CLARKE, Dean H. Justifications for Punishment. Contemporary Crises, v. 6, n. 1, p. 25-77, Jan.1982.

DUFF, R. A. et al. Introduction. In: The Trial on Trial. Vl. II. Judgement and Calling to Account. Portland: Hart Publishing, 2006, p. 1-14.

DUFF, R. A. Punishment, communication, and community. Oxford: Oxford University Press, 2001.

DZUR, Albert W. Participatory Democracy and Criminal Justice. Criminal Law and Philosophy, v. 6, p. 115-129, 2012.

DZUR, Albert W.; MIRCHANDANI, Rekha. Punishment and Democracy. The role of public deliberation, v. 9, n. 2, p. 151-175, 2007.

DZUR, Albert W.; MIRCHANDANI, Rekha. Restorative justice and democracy: fostering public accountability for criminal justice. Contemporary Justice Review, v. 14, n. 4, p. 367-381, 2011.

ESPOSITO, Roberto. Bíos: biopolitics and philosophy. Minneapolis: University of Minnesota Press, 2008.

ESPOSITO, Roberto. Communitas: origen y destino de la comunidad. Buenos Aires: Amorrortu, 2012a.

ESPOSITO, Roberto. Comunidad, inmunidad y biopolítica. S. L.: Herder Editorial, 2009.

ESPOSITO, Roberto. Diez pensamientos acerca de la política. S. L.: Fondo de Cultura Económica de España, 2012b.

ESPOSITO, Roberto. Immunitas: The Protection and Negation of Life. Cambridge: Polity Press, 2011.

FEINBERG, Joel. The expressive function of punishment. Monist, 49:3, p. 397-423, Jul.-1965.

FERRAJOLI, Luigi. Derecho y razón. Teoría del garantismo penal. Madrid: Editorial Trotta, 1995.

FOUCAULT, Michel. Em defesa da sociedade. São Paulo: Martins Fontes, 1999.

FOUCAULT, Michel. História da Sexualidade I: a vontade de saber. 13. ed. Rio de Janeiro: Graal, 1988.

GARGARELLA, Roberto. Las teorías de la justicia después de Rawls: Un breve manual de filosofía política. Barcelona: Paidós, 1999. 
GIAMBERARDINO, André Ribeiro. Crítica da pena e justiça restaurativa: a censura para além da punição. Florianópolis: Empório do Direito Editora, 2015.

HAMPTON, Jean. The Moral Education Theory of Punishment. Philosophy and Public Affairs, v. 13, n. 3, p. 208-238, 1984.

HART, H. L. A. Punishment and Responsibility: essays in the philosophy of law. 2. ed. Oxford: Oxford University Press, 2008.

LACEY, Nicola. State punishment: Political principles and community values. London: Routledge, 1988.

LOSANO, Mario. Sistema e estrutura no Direito. V. II. São Paulo: Martins Fontes, 2010.

MATRAVERS, Matt. Political Neutrality and Punishment. Criminal Law and Philosophy, v. 7, p. 217-230, 2013.

METZ, Thaddeus. How to Reconcile Liberal Politics with Retributive Punishment. Oxford Journal of Legal Studies, v. 27, n. 4, p. 683-705, 2007.

MORRIS, Alisson. Criticando os Críticos: Uma Breve Resposta aos Críticos da Justiça Restaurativa. In: BASTOS, Márcio Thomaz; LOPES, Carlos; RENAULT, Sérgio Rabello Tamm (Org.). Justiça Restaurativa: Coletânea de Artigos. Brasília: MJ e PNUD, 2005. Disponível em: $<$ https://goo.gl/fhzAVj>. Acesso em: 15 nov. 2015.

NALLI, Marcos. Communitas/Immunitas: a releitura de Roberto Esposito da biopolítica. Revista de Filosofia Aurora, v. 25, n. 37, p. 79-105, jul./dez. 2013.

NINO, Carlos Santiago. Los límites de la responsabilidad penal: una teoría liberal del delito. Buenos Aires: Editorial Astrea, 1980.

RESTA, Eligio. Diritto vivente. Bari: Laterza, 2008.

RICOUER, Paul. Justiça e vingança. In: O Justo 2: justiça e verdade e outros estudos. São Paulo: WMF Martins Fontes, 2008, p. 251-260.

ROSENBLATT, Fernanda Fonseca. Um olhar crítico sobre o papel da comunidade nos processos restaurativos. Sistema Penal e violência, v. 6, n. 1, p. 43-61, 2014.

SHAPLAND, J.; ROBINSON, G.; SORSBY, A. Restorative justice in practice. London: Routledge, 2011.

SICA, Leonardo. Justiça restaurativa e mediação penal: o novo modelo de justiça criminal e de gestão do crime. Rio de Janeiro: Lúmen Juris, 2007.

ZEHR, Howard. The little book of Restorative Justice. In: ZEHR, Howard et al. The Big Book on Restorative Justice. Four Classic Justice \& Peacebuilding Books in One Volume. New York: Good Books, 2015, p. 1-108. 
Clara Maria Roman Borges

Mestre e Doutora em Direito pela UFPR. Professora Associada no Curso de Graduação e no Programa de Pós-graduação em Direito da UFPR. Professora no Curso de Direito da Universidade Positivo (Curitiba, PR, Brasil).E-mail: romanborges@uol.com.br

Nikolai Olchanowski

Mestre e Doutorando em Direito pela UFPR. Professor no Curso de Direito da Fundação Universidade do Contestado (Mafra, SC, Brasil).E-mail: nikolai.olchanowski@gmail.com 